\title{
USe OF Augmented Reality TeChNOLOgy in Population Protection AND Crisis MANAGEMENT
}

\author{
Martin Dzermansky, Lukas Snopek, Katerina Vichova, Martin Ficek \& Jakub Rak
}
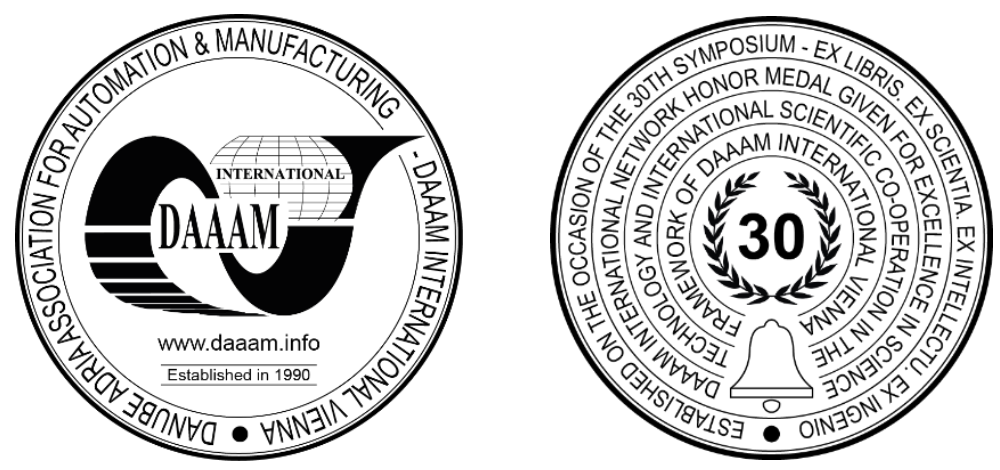

This Publication has to be referred as: Dzermansky, M[artin]; Snopek, L[ukas]; Vichova, K[aterina]; Ficek, M[artin] \& Rak, J[akub] (2021). Use of Augmented Reality Technology in Population Protection and Crisis Management, Proceedings of the 32nd DAAAM International Symposium, pp.0408-0414, B. Katalinic (Ed.), Published by DAAAM International, ISBN 978-3-902734-33-4, ISSN 1726-9679, Vienna, Austria

DOI: $10.2507 / 32$ nd.daaam.proceedings.060

\begin{abstract}
Population protection and crisis management are some of the most-watched areas today. With the growing emergencies and crises, there is also a need to inform the population more about the possible effects, prevent them, or deal with them. For this purpose, the use of software applications is offering. In the last years, there is a growing trend in augmented reality technology, which can also be applied to mobile applications and can be slowly ranking among the most effective future technologies. This article describes the possible application of augmented reality technology in population protection and crisis management. The explanation, experimental, and modelling methods were used to make the article, by which the augmented reality model was applied to the Hololens 2 glasses. Blender and Unreal Engine software were used to create modelling and augmented reality.
\end{abstract}

Keywords: augmented reality; crisis management; Hololens; population protection; technology.

\section{Introduction}

Population protection represents the fulfilment of tasks in planning, organization, and activities to prevent the occurrence and ensure preparedness for an emergency and crisis management, which fulfils the role of security risk analysis. The preparation and the ability of the population to respond to emergencies is a significant problem today. People lack information on how to behave during individual emergencies and how to respond to them. Most of the data can inhabitants found on the websites of cities and municipalities that publish this information. Still, only a tiny part of the population finds this information and gets acquainted with it. Another aspect of the population does not know that they will find this information on their town or village websites.

One way to protect the population is to use SW support for population protection and crisis management. Today, it offers the possibility of using augmented reality technology. This technology is possible to apply to smart devices too. Therefore, it represents the easiest way to train the population or inform and respond to an emergency. This article presents the possible application of augmented reality technology in population protection and crisis management. The work aims to create a functional model based on accurate map data and shows critical infrastructure objects in the selected area. Hololens 2 glasses are used to display created models and applied in augmented reality. 


\section{Augmented reality}

Augmented reality (AR) is one of the variations of the virtual environment (VE) or virtual reality (VR). The difference between augmented reality and the more commonly used virtual reality is that virtual reality aims to immerse the user in an artificial world. In contrast, augmented reality receives digital or computer-generated information. This information can take the form of images, audio, video, or tactile or haptic perceptions that overlap in the real world. Augmented reality, therefore, offers the user to perceive the natural world and project virtually created objects into it. Specific components are required for the proper application of augmented reality. The parts needed for augmented reality: [3]

- Computer or mobile device.

- Monitor or another display medium.

- Camera.

- Tracking and sensing systems (GPS, compass, accelerometer) - are included in almost all smart devices.

- Network infrastructure.

- Tags - these are physical objects or places where real and virtual environments are connected. Here, the computer identifies the area where the digital information is to be presented.

- An application or program that runs locally.

- Web services.

- Content Server.

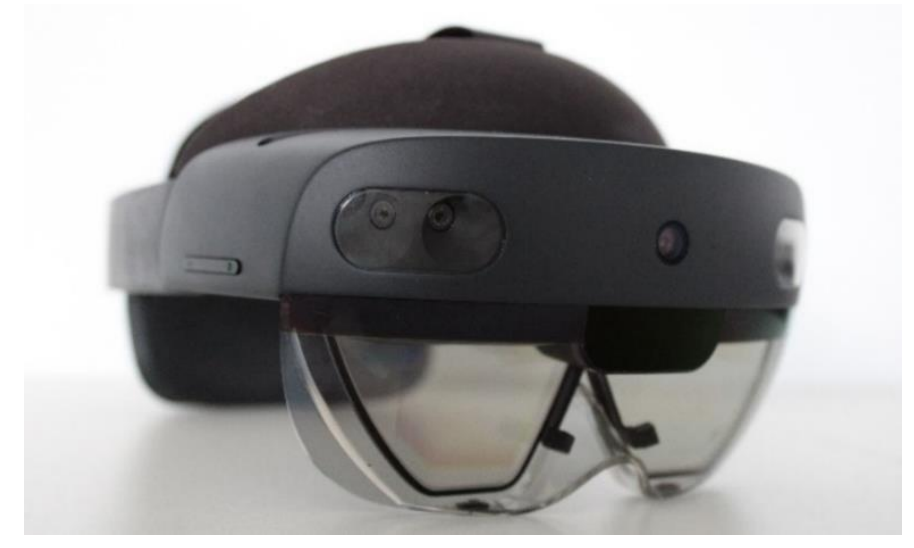

Fig. 1. Hololens 2

The beginnings of augmented reality can be dated back to the 60 s and 70s of the last centuries. In 1968 , the first headworn display was created. This system was called "Damocles' Sword" and was designed by computer scientist and Harvard professor Ivan Sutherland. In 1974, the first artificial reality laboratory was built. The author was the artist and researcher Myron Kruger, and he called this laboratory "Videoplace." In this lab, projection and camera technology were used to emit silhouettes on the screen that surrounded the user for an interactive experience. Using this technology, for example, he was able to write by pointing his finger.

In the 1980s and 1990s, augmented reality flourished. In 1990, the term "augmented reality" was coined by Tom Caudell, and in 1992, one of the first fully functional augmented reality systems, the so-called "Virtual Fixtures," was created. Virtual Fixtures were developed for military personnel and allowed them to control and guide machinery to perform tasks such as training Air Force pilots to fly safer. The year 1998 brought the first application of augmented reality to a sports match. The 1 st $\&$ ten virtual graphics system was used during the NFL game. The technology displayed a yellow line overlaid at the top of the canal and is still used today.

With the advent of the new millennium, new technologies also came. In 2000, an open-source software library called ARToolKit was developed by Hirokazu Kato. It is a package designed to help developers create augmented reality software programs. In 2009, augmented reality was used in print media for the first time, and ARToolKit brought augmented reality to web browsers. In 2013, the MARTA (Mobile Augmented Reality Technical Assistance) application was introduced, which provided Volkswagen with detailed repair instructions in the service manual. In 2014, Google continued to present the first augmented reality glasses, Google Glass. In 2016, competing glasses from Microsoft were introduced, specifically HoloLens glasses, and the year 2017 affected all retailers in the augmented reality sector forever. IKEA has launched an application that allows customers to see home decor options before making a purchase virtually. [4], [5]

An article by Alan Seal on the website vxchnge.com describes the importance of augmented reality technology and the bonuses it brings, describing its importance and the top seven statistics. Anyone could think about why augmented reality technology is important and come up with many things. In this article, Alan Seal mainly presents the contactless interface he has at his disposal compared to other technologies. Competitive virtual reality technology is among the most popular, but it requires a touch interface and other components from which augmented reality has freed itself. 
Among the top seven statistics were:

- Achieve $\$ 70-75$ billion in revenue by 2023.

- The most popular augmented reality game Pokemon GO has been downloaded more than 1 billion times.

- High awareness of augmented reality among people, 70-75\% of people aged 16-44. knows the technology of augmented reality.

- $88 \%$ of midsize companies use augmented reality technology.

- Google Play and the App Store already offer thousands of mobile applications and games using this technology.

- Microsoft's first-generation augmented reality glasses, HoloLens, have sold more than 50,000.

- The Angel List, which gathers information on startups, lists more than 2,000 augmented reality startups. [6]

The future of augmented reality in population protection and crisis management is very open. This work aims to outline the possible use of augmented reality in these areas.

\section{Possibilities of applying augmented reality technology in the field of crisis management and population protection}

Augmented reality presents endless possibilities for expanding the real world. This technology can be found in the industry, such as a teaching background or procedure for employees, games for smart devices, or school teaching materials. Population protection and crisis management are areas that are an integral part of human lives. When considering the connection between augmented reality and these areas, developing much knowledge on working in these areas could be simplified and more efficient.

Population protection and crisis management are not only rules and regulations but also the bodies that represent them. These include the fire brigade, the police of the Czech Republic, and the medical rescue service, which form an integrated rescue system. Augmented reality could play a crucial role in the performance of their duties or exercises in the future. The document "Improving Our View of the World: Police and Augmented Reality Technology" by Thomas J. Cowper and Michael E. Buerger describes possible augmented reality applications to New York City police.

Potential applications of this technology include, for example:

- Intelligent implementation of real-time crime reporting.

- Face data, voiceprints, and other biometric data about known criminals.

- Scalable, three-dimensional maps, complete floor plans of buildings and sewers.

- Better coherence between team members and better coordination with the intervention commander.

- Modulation of sound effects of shots to increase concentration.

- Optical zoom, thermal and infrared imaging.

- AR video, audio, and sensing devices are used to visualize blood samples, bloodstains, and other sensor-detectable forensic data available at crime scenes.

- Coordinated use of robots, unmanned aerial vehicles (UAVs), and police.

- View location, activity, and status information projected into 3D.

- Coordination of widely dispersed units. [1]

One of the possible uses in population protection is the sector of training and education. An article appeared in The Science for Population Protection magazine, published by the Institute for the Population Protection Institute in Lázně Bohdaneč, which deals with augmented reality technology in this sector. This article presents the benefits of technology where it is possible to simulate floods, fires, plan contents, crisis management or disaster management systems and more. No one would intentionally create floods or fires for upbringing or education, so this technology is ideal for projecting these simulations to students.

The technology itself can revive teaching in this area. The authors describe the possibilities of applying this technology in education in two ways. The first is a purely educational journey, in which case it would be printed materials and textbooks that would be enriched with augmented reality elements. The second way is practical, therefore use in the field. [7]

This article aims to point out the possible use of augmented reality technology in population protection and crisis management. In these areas, this technology will be used by linking geographic information systems with augmented reality technology. Critical infrastructure objects will be displayed using models created by Blender and Unreal Engine software. Geographic information systems consist of hardware, software, data, applications, users, and processors. In addition to these elements, geographic information systems are created from raster and vector graphics. The most common use of these systems is in creating maps, which are used, for example, in navigation systems. [2] For this article, Blender software was used, which offers the creation of 3D graphics. This software provides the Blender GIS function, which was used to model the base map, in which building models were uploaded and then uploaded to the Unreal Engine software.

The basis of the model is data from open street maps. For better orientation, Uherske Hradiste was chosen, on which the objects of critical infrastructure are subsequently marked. To make the model as realistic as possible, height quotas are also created, as seen in the image below. The base of the map is wavy due to different altitude quotas. 


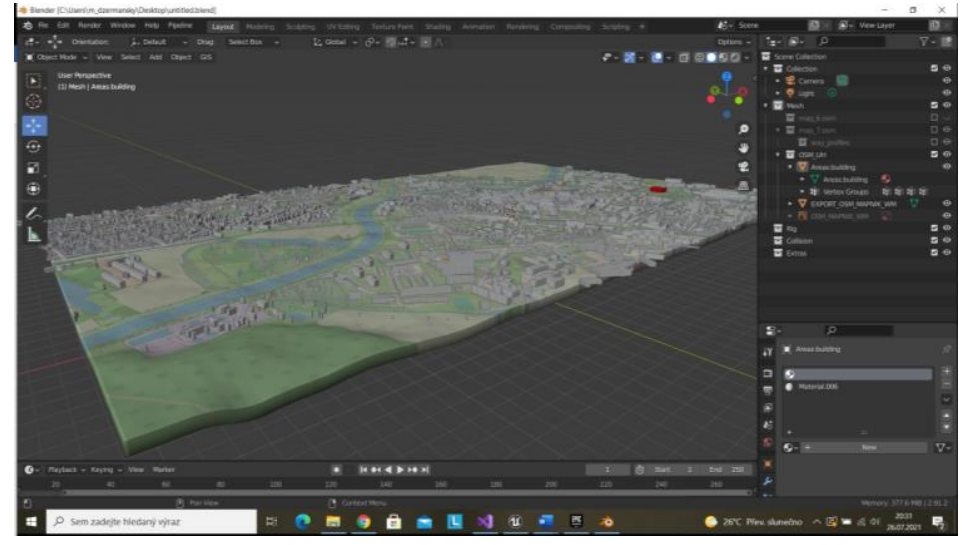

Fig. 2. Blender-GIS

After modification and adjustment of the model, the software Unreal Engine version 4.26.1 was implemented. This software offers work with augmented reality and virtual reality and is known primarily for creating games. After uploading the model to Unreal Engine, it was further modified. The initial settings for working with augmented reality have been altered, and the necessary plugins such as the Hololens plugin, Microsoft Windows Mixed Reality, and others have been downloaded. An important step was the creation of map components or so-called levels. In this case, a total of 5 levels were created.

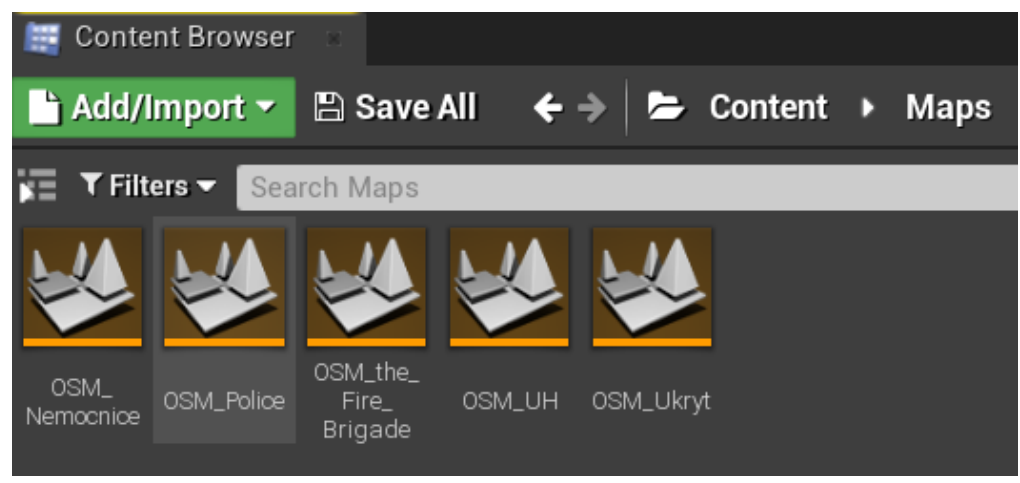

Fig. 3. Levels

Each of these levels contains the same background map but a different marked critical infrastructure object. These objects are:

- hospital,

- police,

- the fire brigade,

- permanent pressure shelter for the civilian population.

The fifth respective first level is the basic background map of Uherske Hradiste, in which the application begins.

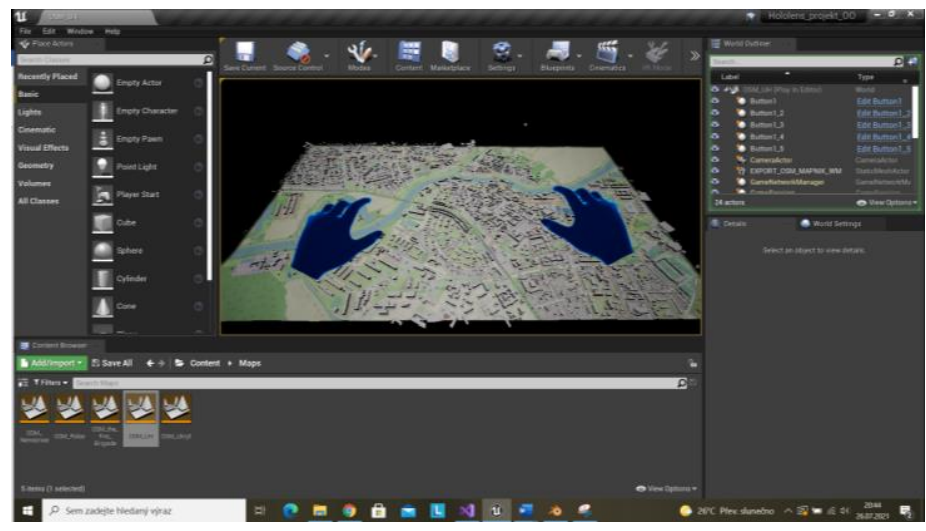

Fig. 4. Basic level 
To switch between individual levels in the application and thus display critical infrastructure buildings, it was necessary to create a functional menu. This menu is created using blueprints and the "UxtPressableButton" function, allowing users to insert clickable buttons.

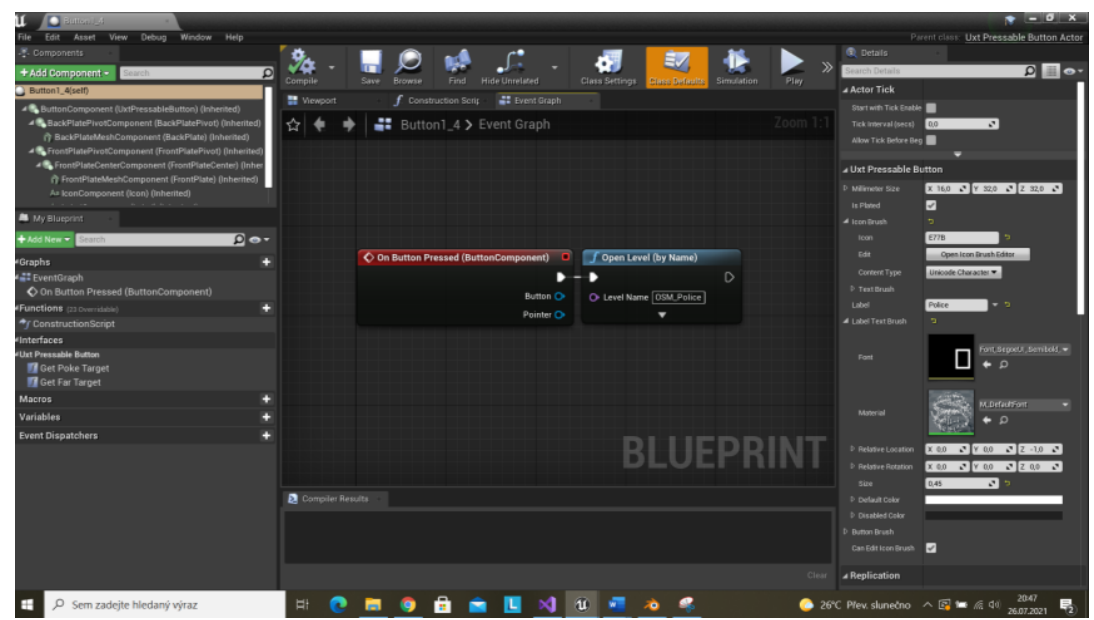

Fig. 5. Example of blueprint

To switch between the created levels (maps), the open level (by name) function was created using blueprints, thanks to which each of the buttons is oriented to a specific level.

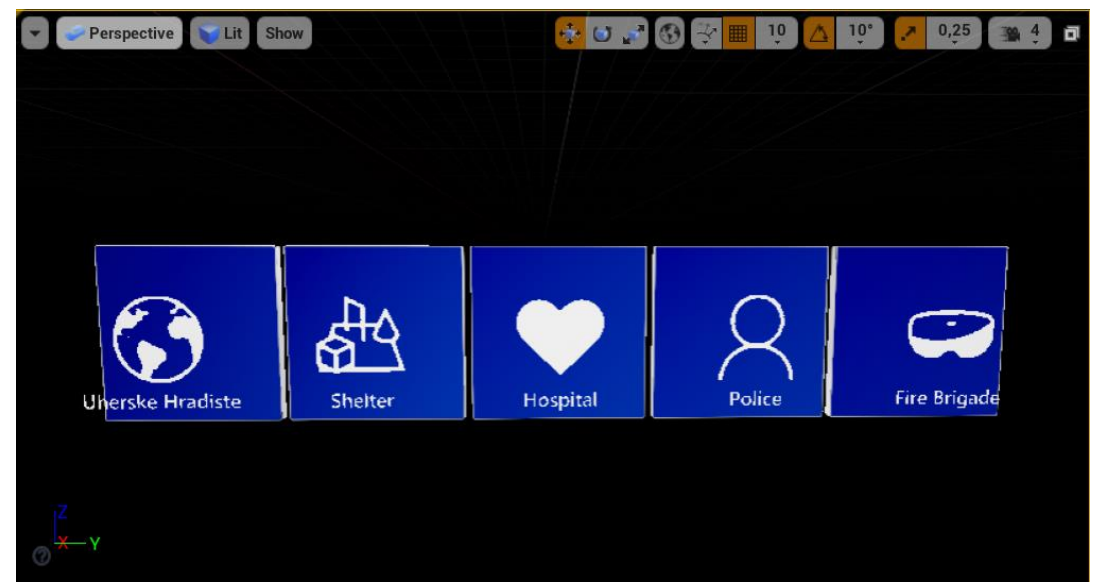

Fig. 6. Main menu

The menu is fully clickable, and the user can switch between individual objects. In the application, it then looks like this. The user launches the application and starts at the Uherske Hradiste level, i.e., on the essential map base.

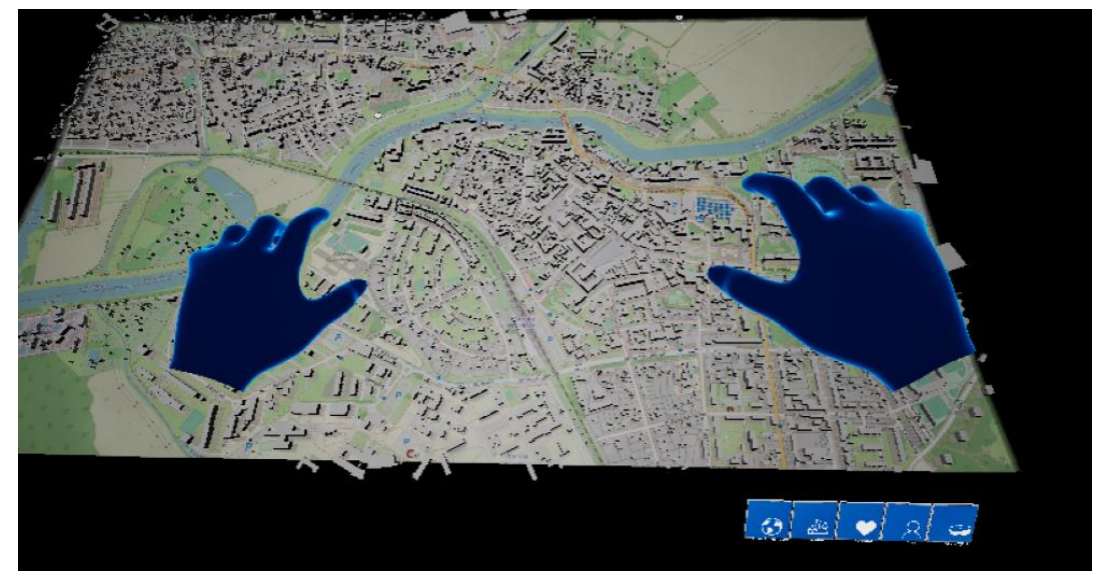

Fig. 7. Start of application in Unreal Engine 
The application starts on the basic map of the Uherske Hradiste. Figure number 7 shows a view from the unreal engine environment. At this point, the user can move or zoom in and out as he wants. Suppose the user decides to view from one critical infrastructure element, which is listed in the menu attached to the map. In that case, all he has to do is click on the component, and the element will be color-coded on the map to be immediately apparent across the scale.

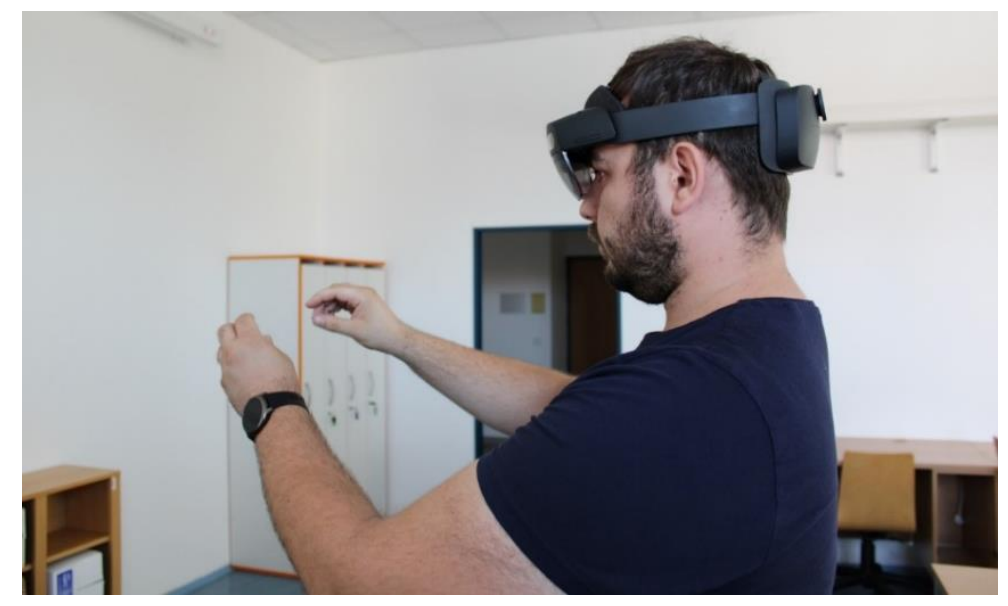

Fig. 8. Start of application in real world

Suppose it is decided to display one of the created elements. In that case, the user presses the button in the menu, and a different colored object will appear in the map base, which indicates the critical infrastructure, in this case, the hospital. The user can use the Hololens 2 glasses to press a button, as in ordinary life, or, if the object is farther away, to aim at it and press the thumb and forefinger to activate the button.

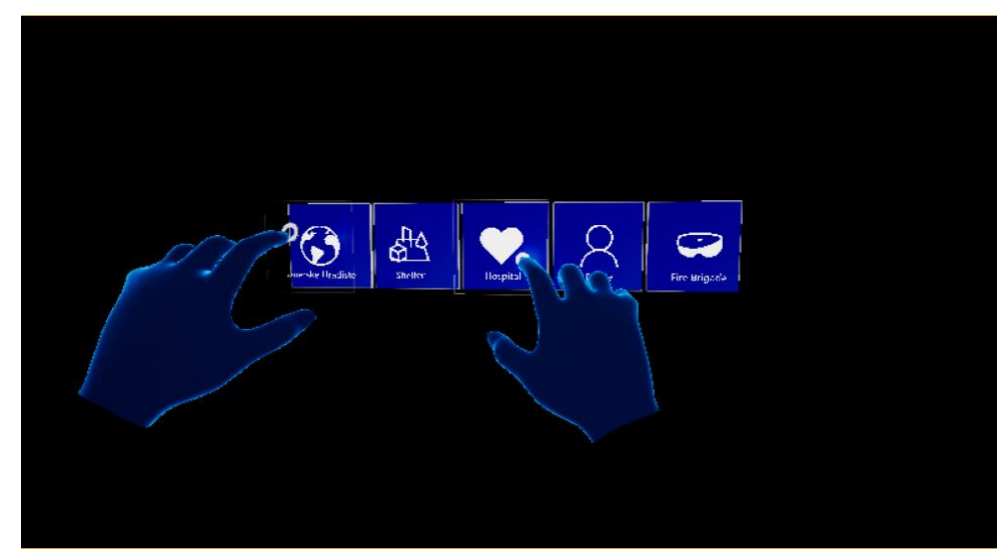

Fig. 9. Pressable buttons in the menu

As with other levels, it is possible to transform and move the object freely. The individual layers can be separated from each other.

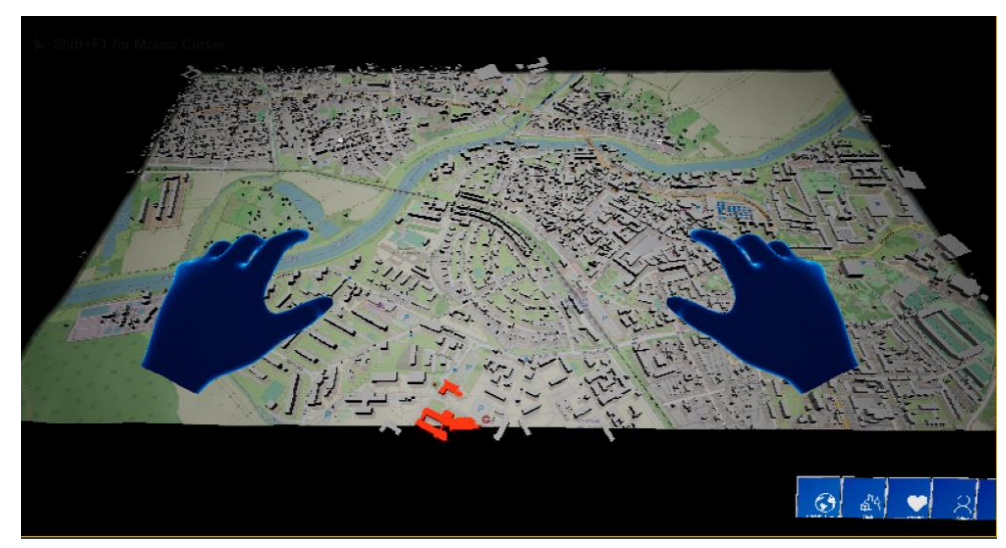

Fig. 10. Changed level with the object of critical infrastructure 
This application offers a more detailed view of the city of Uherske Hradiste in an augmented reality environment, which in this case, is created for the Hololens 2 glasses. These glasses offer fully interactive work with augmented reality. Compared to applications in smart devices, the use of Hololens is much more realistic. Applications created in this way can be used in the future, such as in crisis staff dealing with emergencies, planning logistics nodes for an integrated rescue system, or simulations of events that may affect the population. Thanks to the buildings created in geographical information systems, it is easier to imagine possible damages or better plan rescue and liquidation work.

\section{Methods}

Several scientific methods have been used in this article. Firstly, the explanation method was used to explain population protection, crisis management, and augmented reality technology. Secondly, a modelling method was used to create a model of the city of the Uherske Hradiste and buildings in which the objects of critical infrastructure were colourcoded. Modelling was used in Unreal Engine software for modifying the models too.

The models were created in Blender software, where was used the Blender GIS plugin, which enabled the connection of data from open street maps. The resulting models were exported to the Unreal Engine, in which the models were refined and then converted into augmented reality. Finally, the experimental method was used when the models were recorded in Hololens 2 glasses, and it was possible to project the model into the real world. [8]

\section{Conclusion}

The article aimed to use augmented reality technology in population protection and crisis management by linking geographic information systems and augmented reality technology using Hololens 2 glasses. Firstly, a literature review was conducted, where the authors in their professional publications emphasized the use of augmented reality and its possible implementation in population protection and crisis management. Secondly, for these purposes, the modelling method was used when a model of the city of Uherske Hradiste was created in the Blender software, in which buildings were created using the Blender GIS function. The central part of the article was to present the model that was uploaded to Unreal Engine software version 4.26.1, where levels were created. This model was modified, and critical infrastructure areas were created. Specifically, these are the hospital's buildings, the police, the fire brigade, and the permanent pressure shelter for the civilian population.

The limitations in this article were mainly in the display field options in the Hololens 2 glasses, which are limiting and thus fail to display models to a greater extent. For this reason, the models have been scaled down. The implications of a functional application can be used for emergency simulations, which could be used in practice, for example, in security or crisis staffs, which either analyze it or directly address the event. However, the purchase of glasses is limiting, when glasses would have to be provided for all staff members. Further research aims to create realistic textures and animations that can create an optimal model that could be used in practice and thus help, for example, the integrated rescue system and crisis staff components.

\section{Acknowledgments}

This article was supported by an internal grant project of Tomas Bata University under the number IGA/FAI/2021/003.

\section{References}

[1] Cowper, T. \& Buerger, M. (2003). Improving Our View of the World: Police and Augmented Reality Technology [online]. In: . New York: FBI. Available from: https://www.fbi.gov/file-repository/stats-servicespublications-police-augmented-reality-technology-pdf/view

[2] Dempsey, C. (2021). What is GIS. https://www.gislounge.com/what-is-gis/ [online]. California: www.gislounge.com. Available from: https://www.gislounge.com/what-is-gis/

[3] Kipper, G. \& Rampolla, J. (c2013). Augmented reality: an emerging technologies guide to AR. Waltham: Syngress. ISBN 9781597497336.

[4] Poetker, B. (2019). History of Augmented Reality. Learning Hub [online]. Chicago: Learning Hub. Available from: https://learn.g2.com/history-of-augmented-reality

[5] Schmalstieg, D. \& Höllerer, T. (2016). Augmented reality: principles and practice. Addison Wesley: Boston. ISBN 9780321883575.

[6] Seal, A. (2020). Top 7 Augmented Reality Statistics for 2020. Www.vxchnge.com [online]. Cleveland: www.vxchnge.com. Available from: https://www.vxchnge.com/blog/augmented-reality-statistics

[7] Tomanová, K.; Smetana, M.; Kavan, Š.; Rathauský, Z. \& Mudrochová, S. (2020). Využití rozšířené reality pro př́ípravu a vzdělávání obyvatelstva. The Science for Population Protection. Available from http://www.populationprotection.eu/prilohy/casopis/42/366.pdf

[8] Závěrečná práce - metodika, c2007-2013. Lorenc.info [online]. Praha: VŠE. From http://lorenc.info/zaverecneprace/metodika.htm 